\title{
Influence of dietary Spirulina inclusion and lysozyme supplementation on the longissimus lumborum muscle proteome of newly weaned piglets
}

\author{
David M. Ribeiro $^{\mathrm{a}, 1}$, Cátia F. Martins ${ }^{\mathrm{a}, \mathrm{b}, 1}$, Josipa Kuleš ${ }^{\mathrm{c}}$, Anita Horvatićc ${ }^{\mathrm{c} d}$, Nicolas Guillemin ${ }^{\mathrm{c}}$, \\ João P.B. Freire ${ }^{a}$, P. David Eckersall ${ }^{\text {c,e }}$, André M. Almeida ${ }^{a, *}, 2$, José A.M. Prates ${ }^{\mathrm{b}, 2}$ \\ ${ }^{a}$ LEAF - Linking Landscape, Environment, Agriculture and Food, Instituto Superior de Agronomia, Universidade de Lisboa, 1349-017 Lisboa, Portugal \\ ${ }^{\mathrm{b}}$ CIISA - Centro de Investigação Interdisciplinar em Sanidade Animal, Faculdade de Medicina Veterinária, Universidade de Lisboa, 1300-477 Lisboa, Portugal \\ ${ }^{\mathrm{c}}$ Laboratory of Proteomics, Internal Diseases Clinic, Faculty of Veterinary Medicine, University of Zagreb, Heinzelova 55, 10000 Zagreb, Croatia \\ ${ }^{\mathrm{d}}$ Department of Chemistry and Biochemistry, Faculty of Food Technology and Biotechnology, University of Zagreb, Pierottijeva 6, 10000 Zagreb, Croatia \\ ${ }^{\mathrm{e}}$ Institute of Biodiversity, Animal Health and Comparative Medicine, College of Medicine, Veterinary Medicine and Life Sciences, University of Glasgow, Glasgow G61 \\ $1 Q H, U K$
}

\section{A R T I C L E I N F O}

\section{Keywords:}

Spirulina

Carbohydrate-active enzymes (CAZyme)

Weaned piglet

Muscle proteome

\begin{abstract}
A B S T R A C T
Arthrospira platensis (Spirulina) is a microalga with a high content of crude protein. It has a recalcitrant cell wall that limits the accessibility of the animal endogenous enzymes to its intracellular nutrients. Enzymatic supplementation aiming to degrade cell walls could benefit microalgae digestibility. The objective of this study was to evaluate the impact of dietary Spirulina and lysozyme supplementation over the muscle proteome of piglets during the post-weaning stage. Thirty piglets were randomly distributed among three diets: control (no microalga), SP (10\% Spirulina) and SP + L ( $10 \%$ Spirulina $+0.01 \%$ lysozyme). After 4 weeks, they were sacrificed and samples of the longissimus lumborum muscle were taken. The muscle proteome was analysed using a Tandem Mass Tag (TMT)-based quantitative approach. A total of 832 proteins were identified. Three comparisons were computed: SP vs Ctrl, SP + L vs Ctrl and SP + L vs SP. They had ten, four and twelve differentially abundant proteins. Glycogen metabolism and nutrient reserves utilization are increased in the SP piglets. Structural muscle protein synthesis increased, causing higher energy requirements in SP $+\mathrm{L}$ piglets. Our results demonstrate the usefulness of proteomics to disclose the effect of dietary microalgae, whilst unveiling putative mechanisms derived from lysozyme supplementation. Data available via ProteomeXchange with identifier PXD024083. Significance: Spirulina, a microalga, is an alternative to conventional crops which could enhance the environmental sustainability of animal production. Due to its recalcitrant cell wall, its use requires additional measures to prevent anti-nutritional effects on the feeding of piglets in the post-weaning period, during which they endure post-weaning stress. One of such measures could be CAZyme supplementation to help degrade the cell wall during digestion. Muscle proteomics provides insightful data on the effect of dietary microalgae and enzyme activity on piglet metabolism.
\end{abstract}

\section{Introduction}

Global population is rapidly increasing, as are living standards, which are expected to greatly increase the demand and price of animal products, such as meat or eggs [1]. Maize and soybean meal (SBM) are extensively used in monogastric animal diets around the world [2]. Consequently, the demand for these conventional feedstuffs will likely increase in parallel to that of animal products. Soybean meal and maize are essentially produced in American countries, like Argentina, Brazil and the United States of America [3], and are exported to major markets for animal production, namely China and the European Union. The production of these crops raises questions on its sustainability [4], particularly given the high transportation costs and resulting greenhouse gas emissions. Therefore, it is important to find sustainable and viable alternatives that can contribute towards enhanced animal production and hence replace such feedstuffs. Microalgae are increasingly

\footnotetext{
* Corresponding author.

E-mail address: aalmeida@isa.ulisboa.pt (A.M. Almeida).

${ }^{1}$ Both authors contributed equally to this paper and should be considered co-authors.

2 André Martinho de Almeida and José António Mestre Prates have equal contributions and are joint senior authors.
} 
considered as an interesting alternative [2].

Microalgae, a large group of uni- or multi-celular organisms, are divided into 4 major classes: diatoms (Bacillarophyceae), green (Chlorophyceae), golden (Chrysophyceae) and blue-green (Cyanophyceae) algae [2]. Spirulina, Arthrospira platensis, belongs to the latter. It has a particularly high crude protein (CP) content (62-72\% in dry matter $\mathrm{DM}$ ) and up to $44.2 \%$ poly-unsaturated fatty acids (PUFA) in total fatty acids [1], which makes it a potentially viable alternative to proteinaceous feedstuffs such as SBM. However, like other microalgae such as Chlorella vulgaris [5], it poses several challenges when included in monogastric diets. Indeed, and due to its recalcitrant cell wall [6], nutrient availability is very limited. Therefore, animal nutritionists should establish strategies to improve nutrient digestibility when formulating diets including the raw biomass of microalgae. One of such strategies is the supplementation of carbohydrate-active enzymes (CAZymes) to promote the degradation of the cell wall [6].

Piglet nutrition is a very important field within the pig industry. Adequate pre-weaning nutrition guarantees the full development of the piglet, whilst promoting the intake of solid feed for a better adaptation to the post-weaning period [7]. This is particularly important in Mediterranean countries, given the demand for suckling piglets to produce roasted piglet traditional products, such as Leitão da Bairrada in Portugal, Cochinillo Asado in Spain and Porcheddu in Italy [8,9]. The production of these regional dishes often depends on autochthonous breeds, such as the Portuguese Bísaro. Around $70 \%$ of weaned piglets of this breed are slaughtered for this purpose [9]. The post-weaning period is very critical. Post-weaning stress (PWS) is associated with the adaptation to nutritional, social and environmental changes, often accompanied with decreased growth and immune depression, where issues such as diarrhoea have also a significant detrimental effect [10]. To deal with this period, high-quality feeds are required. Current literature presents several results where the incorporation of small levels of microalgae improves animal performance, intestinal structure, and feed conversion, due to the promotion of beneficial bacteria in the gut, such as Lactobacillus [1]. Higher levels of incorporation, to supply major nutrients, have been reported with defatted microalgae biomass $[11,12]$. Ekmay et al. [12] reported that the use of proteolytic enzymes improves the final weight of piglets fed with $10 \%$ Desmodesmus sp. defatted biomass compared to piglets of control. Our team, in a recent paper, reported that feeding piglets with $10 \%$ whole Spirulina, regardless of enzyme supplementation, lowered growth performance, averaging 9.1\% decrease in final weight, compared to the control. Lysozyme, despite achieving the degradation of the cell wall, did not improve the digestibility of Spirulina, because of the resistance of its protein against endogenous digestive enzymes, which increases digesta viscosity [8]. Interestingly, knowledge on the physiological impact of the use of dietary microalgae in pig tissues proteome is absent from available literature.

Omics (genomics, transcriptomics, proteomics and metabolomics) technologies are approaches that enable the study of tissue metabolism at the molecular level, as affected by a pre-determined factor. Proteomics allows the study of the proteome, which is the group of proteins present in a given tissue at a given time point. Farm animal proteomics in particular, has gained increased attention due to its numerous applications, from improving reproduction/selection programmes to product quality and traceability $[13,14]$. Pig production has benefited from this technology $[15,16]$. Using omics to study complex physiological aspects, such as stress response in pigs, has allowed the discovery of several pathways and putative biomarkers indicating stress susceptibility or resilience [16]. Biomarkers, that can be established using proteomics, have the potential to introduce a valuable feedback system, in which the practices of the several production levels (reproduction, feeding, slaughter, etc.) can be monitored and evaluated to improve decision making [17]. Recent studies published using proteomics in pigs fed with different protein levels [18], under protein restriction [19] and different diet composition [20] clearly demonstrate the interest of this tool in swine nutrition and physiology. To the best of our knowledge, no study has been published on the effect of dietary microalgae on the proteome of any swine tissue. Indeed, and to our knowledge, such an approach was only conducted by our research team in a recent study on the effect of Nannochloropsis oceanica dietary inclusion on the rabbit muscle proteome [21].

Recent literature lacks the evaluation of the impact of dietary factors on pig tissue proteomes. Those that do study this subject, do not focus on either Spirulina (or microalgae for that matter) or CAZyme dietary inclusion as influencing factors. It is our perspective that the potential for the use of proteomics in the field of pig nutrition is immense. With it, we can analyse dietary effects at the molecular level: nutrient metabolism, mechanisms of adaptation to detrimental feedstuffs/restrictions, among many other approaches. When studying novel feedstuffs, scientists benefit from the use of these state-of-the-art technologies. These allow an in-depth characterization of their impact on animal metabolism, which goes beyond the analysis of classical data (such as digestibility coefficients). In fact, it allows studying the effect after nutrient digestibility and how the animal in question copes with it. Thus, the objective of this study was to evaluate the effect of dietary Spirulina and lysozyme supplementation on the longissimus lumborum muscle proteome of recently weaned piglets.

\section{Materials and methods}

\subsection{Animals and diets}

The procedures describing animals and experimental conditions have been reported elsewhere [8]. Briefly, 30 commercial male piglets ([Large White $\times$ Landrace] $\times$ Pietrain), weaned at 28 days of age and with an average live weight (LW) of $12.0 \pm 0.89 \mathrm{~kg}$ were evenly distributed in pens to form three groups $(n=10)$. Each group received a different experimental diet: control, control with $10 \%$ Spirulina (SP) and control with $10 \%$ Spirulina supplemented with $0.01 \%$ of lysozyme (Sigma 62,971, Sigma-Aldrich Ltd. St. Louis, MO, USA - SP + L). The composition of experimental diets was published previously and is shown for contextual reasons in Supplementary Table 1. For a period of 28 days, feed and water was available ad libitum and animals were weighed weekly. At the end of the experimental period, animals were unsensitised by electrical stunning and slaughtered by exsanguination, following standard procedures of commercial abattoirs. Samples of longissimus lumborum muscle from each experimental group were removed from the left side of the carcass following the last thoracic vertebrae. They were subsequently frozen and stored at $-80^{\circ} \mathrm{C}$ until further analysis.

\subsection{Animal welfare statement}

All procedures used were reviewed by the Ethics Committee of the Instituto Superior de Agronomia and approved by the Animal Care Committee of the National Veterinary Authority (Direção Geral de Alimentação e Veterinária, Lisbon, Portugal): reference 0421/000/000/ 2017, date 30-06-2017, following the specific guidelines of national and European Union legislation (Directive 2010/63/EU).

\subsection{Protein extraction}

Five muscle samples per experimental group were randomly selected and used for proteomic analysis. Cold cut frozen muscle samples were homogenized in $500 \mathrm{ml}$ lysis buffer (100 mM TEAB, 2\% SDS) using an Omni TH220 homogenizer (Omni International, Kennesaw, USA), followed by 2 cycles of sonication at maximum amplitude (Qsonica, Newtown, USA) on ice. After centrifugation at $16000 \times g$ at $4{ }^{\circ} \mathrm{C}$ for 30 min, clarified supernatant was transferred into a new tube. 


\subsection{Protein identification and quantification using TMT approach}

Sample extracts from each group were processed using the filter aided sample preparation (FASP) protocol and Tandem Mass Tag (TMT)based quantitative approach. In brief, total protein concentration was determined using BCA assay (Thermo Scientific, Rockford, USA). For each sample and internal standard (pool of all samples), an amount of $35 \mu \mathrm{g}$ of total proteins was diluted to a volume of $200 \mu \mathrm{l}$ using urea buffer ( $8 \mathrm{M}$ urea in $0.1 \mathrm{M}$ Tris- $\mathrm{HCl} \mathrm{pH} 8.5$ ) and subjected to the FASP protocol with some modifications [22]. Samples were transferred to the 10-kDa membrane filter units (Microcon YM-10, Merck Millipore), centrifuged $\left(13,000 \times g, 20 \mathrm{~min}, 20^{\circ} \mathrm{C}\right)$ and washed subsequently with $200 \mu \mathrm{l}$ of FASP-urea buffer. Proteins were alkylated (50 mM IAA, $20 \mathrm{~min}$ at room temperature in the dark), washed twice with urea buffer and then twice with triethyl ammonium bicarbonate $(100 \mathrm{mM} \mathrm{pH} \mathrm{8.5)}$ (TEAB, Thermo Scientific, Rockford, USA) followed by centrifugation. Proteins were digested by trypsin gold (Promega, enzyme-to-protein ratio $1: 35, \mathrm{v} / \mathrm{v}$, at $37{ }^{\circ} \mathrm{C}$ overnight). Peptides were then collected from filter by centrifugation, washed with $50 \mu \mathrm{l}$ of TEAB/ACN (1:1, v/v), centrifuged and vacuum dried. TMT tenplex reagents (Thermo Scientific, Rockford, IL, USA) for muscle samples were prepared according to manufacturer's procedure, as described previously [23]. An amount of $19 \mu \mathrm{l}$ of specific TMT label was added to each sample for labelling (60 min, room temperature). The reaction was quenched using 5\% hydroxylamine (Sigma-Aldrich, St. Louis, MO, USA). Nine TMT-modified samples were randomly combined with the internal standard (labelled with TMT $m / z 126$ ), aliquoted, dried and stored at $-20{ }^{\circ} \mathrm{C}$ for further analysis. In total, two tenplexes were prepared for muscle samples.

High resolution LC-MS/MS analysis of TMT-labelled peptides was carried out using an Ultimate 3000 RSLCnano system (Dionex, Germering, Germany) coupled to a $Q$ Exactive Plus mass spectrometer (Thermo Fisher Scientific, Bremen, Germany). Peptides were dissolved in loading solvent ( $1 \%$ ACN, $0.1 \%$ formic acid) and loaded onto the trap column (C18 PepMap100, $5 \mu \mathrm{m}, 100 \mathrm{~A}, 300 \mu \mathrm{m} \times 5 \mathrm{~mm}$ ), desalted for 12 min at the flow rate of $15 \mu \mathrm{l} / \mathrm{min}$ and separated on the analytical column (PepMap ${ }^{\text {TM }}$ RSLC C18, $50 \mathrm{~cm} \times 75 \mu \mathrm{m}$ ) using a linear gradient of $5-45 \%$ mobile phase B $(0.1 \%$ formic acid in $80 \%$ ACN) over $120 \mathrm{~min}, 45 \%$ to $90 \%$ for $2 \mathrm{~min}$, held at $80 \%$ for $2 \mathrm{~min}$ and re-equilibrated at $5 \%$ B for 20 $\min$ at the flow rate of $300 \mathrm{nl} / \mathrm{min}$. Mobile phase A consisted of $0.1 \%$ formic acid in water. Ionisation was achieved using nanospray Flex ion source (Thermo Fisher Scientific, Bremen, Germany) containing a 10 $\mu \mathrm{m}$-inner diameter SilicaTip emitter (New Objective, USA). The MS operated in positive ion mode using DDA Top8 method. Full scan MS spectra were acquired in range from $\mathrm{m} / \mathrm{z} 350.0$ to $\mathrm{m} / \mathrm{z} 1800.0$ with a resolution of 70,000, $110 \mathrm{~ms}$ injection time, AGC target $1 \times \mathrm{E} 6, \mathrm{a} \pm 2.0$ $\mathrm{Da}$ isolation window and the dynamic exclusion $30 \mathrm{~s}$. HCD fragmentation was performed at step collision energy ( $29 \%$ and $35 \%$ NCE) with a resolution of 17,500 and AGC target of $2 \times$ E5. Precursor ions with unassigned charge state, as well as charge states of +1 and more than +7 were excluded from fragmentation.

Acquired MS/MS spectra were analysed for protein identification and quantification using the SEQUEST algorithm implemented into Proteome Discoverer (version 2.0., ThermoFisher Scientific). Database search against Sus scrofa FASTA files (downloaded from Uniprot database $04 / 18 / 2018,77,933$ entries) was performed according to the following parameters: two trypsin missed cleavage sites, precursor and fragment mass tolerances of $10 \mathrm{ppm}$ and $0.02 \mathrm{Da}$, respectively; carbamidomethyl (C) fixed peptide modification, oxidation (M), deamidation (N,Q) and TMT sixplex (K, peptide N-terminus) dynamic modifications. The false discovery rate (FDR) for peptide identification was calculated using the Percolator algorithm in the Proteome Discoverer workflow based on the search results against a decoy database and was set at $1 \%$ FDR. At least two unique peptides and 5\% FDR were required for reporting confidently identified proteins.

Protein quantification was accomplished by correlating the relative intensities of reporter ions extracted from tandem mass spectra to that of
Initial weight $(\mathrm{kg})$
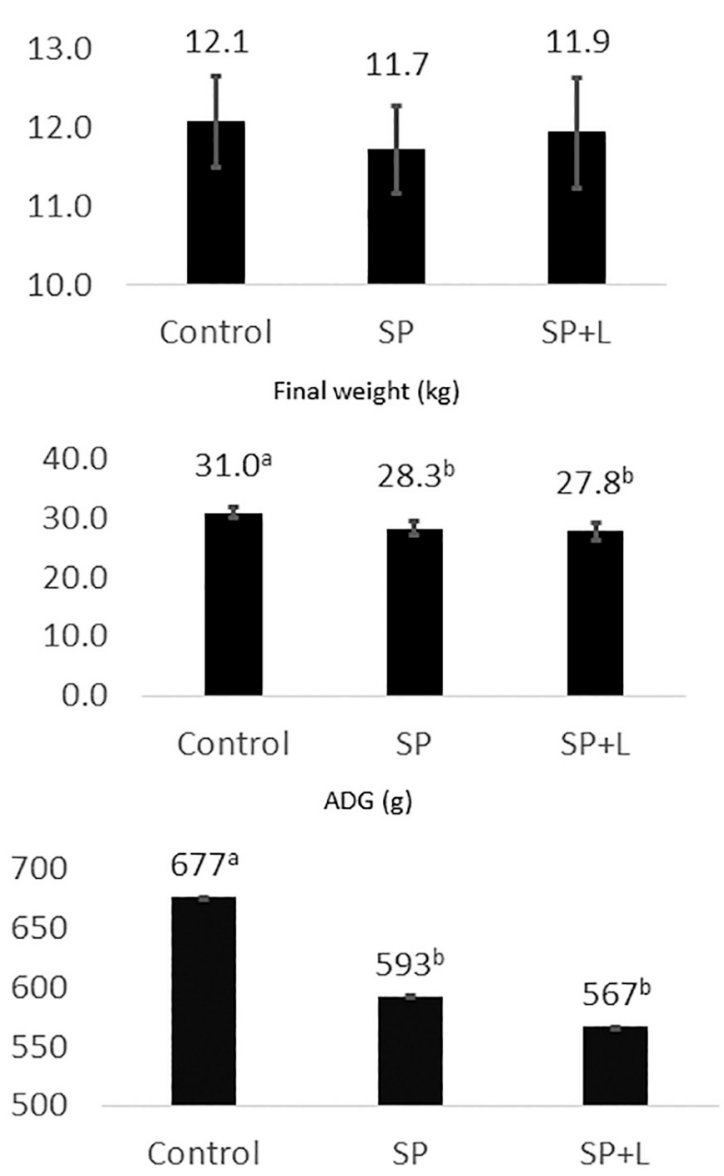

Fig. 1. Initial weight, final weight, and average daily gain (ADG) of piglets fed with the different dietary treatments: control, SP (10\% Spirulina) and SP + L (10\% Spirulina $+0.01 \%$ lysozyme). Means with different superscripts are significantly different $(\mathrm{p}<0.05)$. Statistical analysis performed elsewhere [8].

the peptides selected for MS/MS fragmentation. The internal standard was used to compare relative quantification results for each protein between the experiments.

The mass spectrometry proteomics data have been deposited to the ProteomeXchange Consortium via the PRIDE [23] partner repository with the dataset identifier PXD024083.

\subsection{Statistical analysis}

Statistical analysis followed the procedures reported elsewhere [24-26]. All statistical analyses were carried out using the R software, under the R Studio environment [27]. A Wilcoxon test was performed to detect significant differences using the stats package. Fold change for each group comparison was obtained by using the $\log 2$ (Mean A/Mean B) function. When $p<0.05$, proteins were considered significantly different between comparisons. Gene ontology classification was performed using PANTHER [28].

\section{Results}

\subsection{Animal performance}

Animal performance and feed digestibility were previously reported [8] and are briefly presented in this work for contextual purposes only. Fig. 1 depicts the performance results obtained. Overall, the control group had statistically significant higher final weight compared to the other groups. The same relation was found for average daily gain (ADG). 
Table 1

Differentially abundant proteins for SP vs control comparison in the longissimus lumborum muscle.

\begin{tabular}{|c|c|c|c|}
\hline $\begin{array}{l}\text { Accession } \\
\text { number }\end{array}$ & Protein description [Sus scrofa] & p-value & $\begin{array}{l}\text { Fold } \\
\text { change }\end{array}$ \\
\hline A0A287BNL5 & $\begin{array}{l}\text { Uncharacterized protein OS=Sus scrofa } \\
\mathrm{OX}=9823 \mathrm{PE}=4 \mathrm{SV}=1\end{array}$ & 0.01587 & -0.70321 \\
\hline F1SS62 & $\begin{array}{l}\text { Myosin heavy chain } 8 \text { OS }=\text { Sus scrofa } \\
\text { OX }=9823 \mathrm{GN}=\text { MYH8 PE }=3 \mathrm{SV}=3\end{array}$ & 0.01587 & -0.54227 \\
\hline Q19PY2 & $\begin{array}{l}\text { Alpha-1,4 glucan phosphorylase } \\
\mathrm{OS}=\text { Sus scrofa } \mathrm{OX}=9823 \mathrm{GN}=\mathrm{PYGM} \\
\mathrm{PE}=2 \mathrm{SV}=2\end{array}$ & 0.01945 & -0.46302 \\
\hline F1S557 & $\begin{array}{l}\text { Amylo-alpha-1, 6-glucosidase, 4-alpha- } \\
\text { glucanotransferase OS=Sus scrofa OX } \\
=9823 \mathrm{GN}=\text { AGL PE }=1 \mathrm{SV}=2\end{array}$ & 0.02940 & 0.05859 \\
\hline Q29568 & $\begin{array}{l}\text { Phosphopyruvate hydratase } \\
\text { (Fragment) OS=Sus scrofa } \mathrm{OX}=9823 \\
\mathrm{PE}=2 \mathrm{SV}=1\end{array}$ & 0.04909 & 0.11969 \\
\hline A0A287B441 & $\begin{array}{l}\text { ATP synthase-coupling factor } 6 \text {, } \\
\text { mitochondrial OS=Sus scrofa OX }= \\
9823 \mathrm{GN}=\text { ATP5J PE }=3 \mathrm{SV}=1\end{array}$ & 0.01945 & 0.15757 \\
\hline F1S156 & $\begin{array}{l}\text { Synaptopodin } 2 \mathrm{OS}=\text { Sus scrofa OX }= \\
9823 \mathrm{GN}=\mathrm{SYNPO} 2 \mathrm{PE}=1 \mathrm{SV}=3\end{array}$ & 0.01565 & 0.21333 \\
\hline H6TBNO & $\begin{array}{l}\text { Thioredoxin OS }=\text { Sus scrofa } \mathrm{OX}=9823 \\
\mathrm{GN}=\mathrm{TRX} 1 \mathrm{PE}=2 \mathrm{SV}=1\end{array}$ & 0.02843 & 0.23739 \\
\hline G9F6X8 & $\begin{array}{l}\text { Protein disulfide-isomerase } \mathrm{OS}=\text { Sus } \\
\text { scrofa } \mathrm{OX}=9823 \mathrm{GN}=\mathrm{P} 4 \mathrm{HB} \mathrm{PE}=2 \mathrm{SV} \\
=1\end{array}$ & 0.01945 & 0.33956 \\
\hline A0A287BF33 & $\begin{array}{l}\text { Actin, alpha skeletal muscle } \mathrm{OS}=\text { Sus } \\
\text { scrofa } \mathrm{OX}=9823 \mathrm{GN}=\mathrm{ACTA} 1 \mathrm{PE}=1 \\
\mathrm{SV}=1\end{array}$ & 0.01587 & 0.45446 \\
\hline
\end{tabular}

\subsection{Proteomic analysis}

A total of 832 proteins were successfully identified and quantified in the piglet longissimus lumborum muscle (Supplementary File 1). Three comparisons were made between all experimental groups (Table 1, Fig. 2A). Between SP and control groups, ten proteins were identified with differential abundance. The 10 proteins more abundant in the SP group were mostly involved in catalysis (GO:0003824). These include amylo-alpha-1, 6-glucosidase, 4-alpha-glucanotransferase (AGL), ATP synthase-coupling factor 6 (ATP5J) and protein disulphide-isomerase (P4HB). In contrast, the control group had 4 highly abundant proteins, such as myosin heavy chain 8 (MYM8) and alpha-1,4 glucan phosphorylase (PYGM).

The SP $+\mathrm{L}$ vs Control comparison yielded the lowest number of differentially abundant proteins (Table 2, Fig. 2B). The SP + L group had increased accumulation of apolipoprotein A-I (APOA1), whereas the control had higher accumulation of L-lactate dehydrogenase (LDH) and thioredoxin (TRX1).

Finally, the highest number of differentially abundant proteins were obtained in the SP + L vs SP comparison (Table 3, Fig. 2C). The latter group has higher abundance of four proteins, such as caveolae associated protein 1 (CAVIN1) and alpha-1,4 glucan phosphorylase (PYGM), which have mostly catalytic activity (GO:0003824). In turn, the SP $+\mathrm{L}$ group has higher abundance of structural/contractile apparatus proteins such as tropomyosin 3 (TPM3) and myosin light chains (MYL2, MYL3, MYL10). It also had higher abundance of aconitate hydratase (ACO2).

All results regarding the gene ontology classification of differentially abundant proteins are available in Fig. 3.

\section{Discussion}

Using proteomics to evaluate animal metabolism in nutritionoriented studies has been extensively reported in recent years. However, to our knowledge, the specific evaluation of the inclusion of microalgae effect over pig muscle proteome remains to be established. Recently, the effect of dietary Nannochloropsis oceanica on the rabbit muscle proteome has been described [21]. The authors found that $4.45 \%$

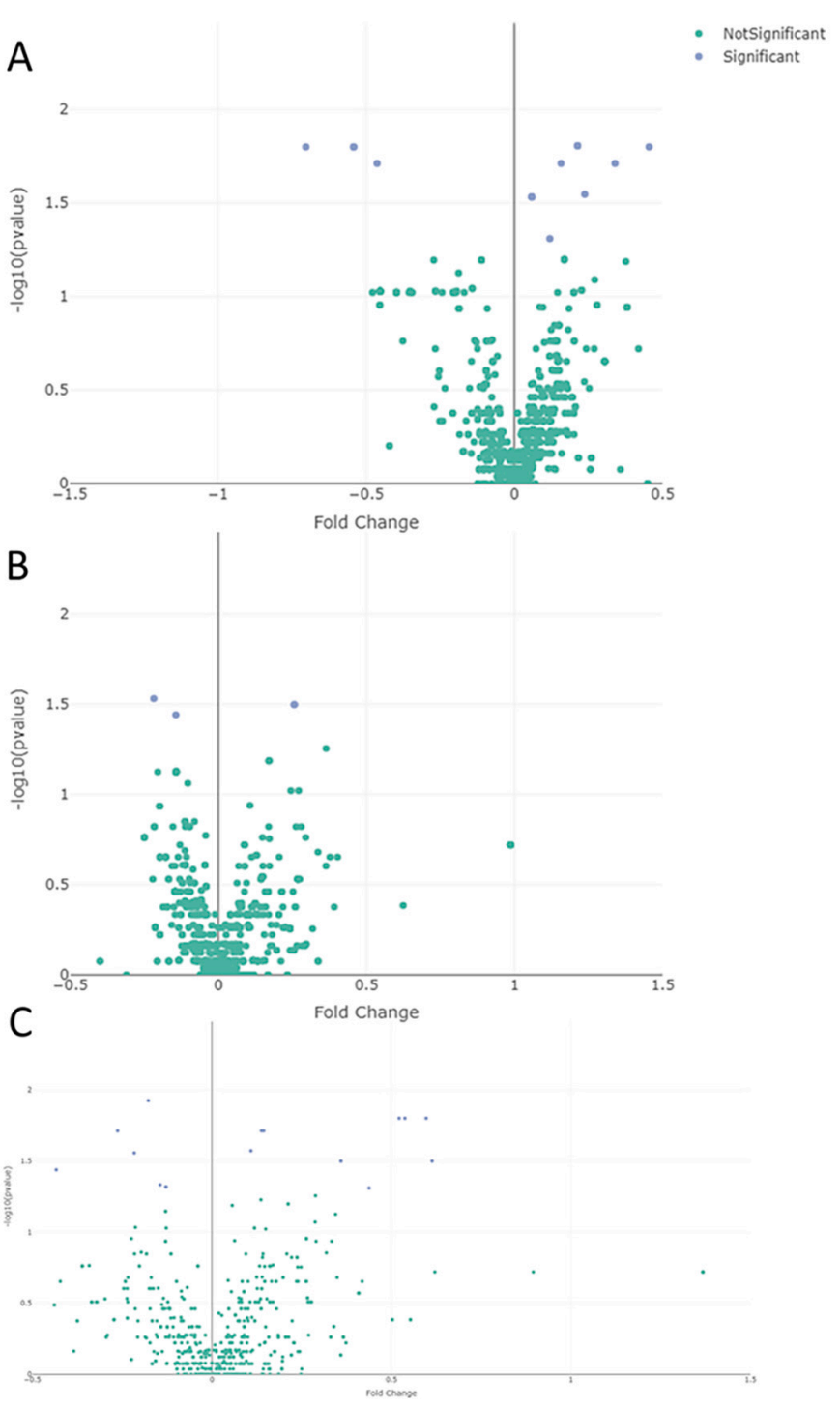

Fig. 2. Volcano plots obtained for each comparison: SP vs Ctrl (A), SP + L vs Ctrl (B) and SP + L vs SP (C). Plots the fold changes of each protein (x-axis) with the p-value (y-axis) obtained from the Wilcoxon test. Significantly different proteins are marked in purple, non-significant are marked in green. (For interpretation of the references to colour in this figure legend, the reader is referred to the web version of this article.)

Table 2

Differentially abundant proteins for SP $+\mathrm{L}$ vs control comparison in the longissimus lumborum muscle.

\begin{tabular}{llll}
\hline $\begin{array}{l}\text { Accession } \\
\text { number }\end{array}$ & Protein description [Sus scrofa] & p-value & $\begin{array}{l}\text { Fold } \\
\text { change }\end{array}$ \\
\hline D2SW96 & $\begin{array}{l}\text { L-lactate dehydrogenase OS=Sus scrofa } \\
\text { OX }=9823 \mathrm{PE}=2 \mathrm{SV}=1\end{array}$ & 0.03615 & -0.14336 \\
K7GM40 & $\begin{array}{l}\text { Apolipoprotein A-I OS }=\text { Sus scrofa OX }= \\
\text { 9823 GN }=\text { APOA1 PE }=3 \text { SV }=2\end{array}$ & 0.03175 & 0.25627 \\
H6TBN0 & $\begin{array}{l}\text { Thioredoxin OS }=\text { Sus scrofa OX }=9823 \\
\text { GN }=\text { TRX1 PE }=2 \text { SV }=1\end{array}$ & 0.02940 & -0.21798 \\
\hline
\end{tabular}

microalga inclusion affected muscle amino acid metabolism and protein turnover, which is possibly related with the recalcitrant cell wall of microalgae. Spirulina, used in the present study, currently lacks a similar analysis. The effect of external enzymes to improve its nutrient availability also warrants further discussion. 
Table 3

Differentially abundant proteins for SP $+\mathrm{L}$ vs SP comparison in the longissimus lumborum muscle.

\begin{tabular}{|c|c|c|c|}
\hline $\begin{array}{l}\text { Accession } \\
\text { number }\end{array}$ & Protein description [Sus scrofa] & $\begin{array}{l}P \\
\text { value }\end{array}$ & $\begin{array}{l}\text { Fold } \\
\text { Change }\end{array}$ \\
\hline Q19PY2 & $\begin{array}{l}\text { Alpha- } 1,4 \text { glucan phosphorylase } \mathrm{OS}=\mathrm{Sus} \\
\text { scrofa } \mathrm{OX}=9823 \mathrm{GN}=\mathrm{PYGM} \mathrm{PE}=2 \mathrm{SV} \\
=2\end{array}$ & 0.037 & -0.43368 \\
\hline A0A2C9F3B2 & $\begin{array}{l}\text { Voltage-dependent anion-selective } \\
\text { channel protein } 1 \mathrm{OS}=\text { Sus scrofa } \mathrm{OX}= \\
9823 \mathrm{GN}=\mathrm{VDAC} 1 \mathrm{PE}=1 \mathrm{SV}=1\end{array}$ & 0.019 & -0.26265 \\
\hline F1SLF0 & $\begin{array}{l}\text { Uncharacterized protein } \mathrm{OS}=\text { Sus scrofa } \\
\mathrm{OX}=9823 \mathrm{GN}=\mathrm{SPR} \mathrm{PE}=1 \mathrm{SV}=3\end{array}$ & 0.012 & -0.17722 \\
\hline A0A287A2G4 & $\begin{array}{l}\text { Caveolae associated protein } 1 \mathrm{OS}=\text { Sus } \\
\text { scrofa } \mathrm{OX}=9823 \mathrm{GN}=\mathrm{CAVIN} 1 \mathrm{PE}=4 \\
\mathrm{SV}=1\end{array}$ & 0.048 & -0.12808 \\
\hline Q0QF26 & $\begin{array}{l}\text { Malate dehydrogenase (Fragment) } \\
\mathrm{OS}=\text { Sus scrofa } \mathrm{OX}=9823 \mathrm{GN}=\mathrm{MDH} 2 \\
\mathrm{PE}=2 \mathrm{SV}=1\end{array}$ & 0.027 & 0.10852 \\
\hline F1SRC5 & $\begin{array}{l}\text { Aconitate hydratase, mitochondrial } \\
\mathrm{OS}=\text { Sus scrofa } \mathrm{OX}=9823 \mathrm{GN}=\mathrm{ACO} 2 \\
\mathrm{PE}=1 \mathrm{SV}=3\end{array}$ & 0.019 & 0.14414 \\
\hline Q2XQY5 & $\begin{array}{l}\text { Tropomyosin } 3 \mathrm{OS}=\text { Sus scrofa OX }= \\
9823 \mathrm{GN}=\operatorname{tpm} 3 \mathrm{PE}=2 \mathrm{SV}=1\end{array}$ & 0.032 & 0.35930 \\
\hline A0A287AIU7 & $\begin{array}{l}\text { Troponin C, slow skeletal and cardiac } \\
\text { muscles OS }=\text { Sus scrofa OX }=9823 \mathrm{GN}= \\
\text { TNNC1 } \mathrm{PE}=1 \mathrm{SV}=1\end{array}$ & 0.049 & 0.43762 \\
\hline A1XQV9 & $\begin{array}{l}\text { MLC2v (Fragment) OS }=\text { Sus scrofa } \mathrm{OX}= \\
9823 \mathrm{GN}=\text { MLC2V PE }=2 \mathrm{SV}=1\end{array}$ & 0.016 & 0.52135 \\
\hline Q8MHY0 & $\begin{array}{l}\text { MYL2 OS }=\text { Sus scrofa OX }=9823 \mathrm{GN}= \\
\text { MLC-2 V PE }=1 \mathrm{SV}=1\end{array}$ & 0.016 & 0.53751 \\
\hline F1RKG0 & $\begin{array}{l}\text { Myosin light chain } 10 \mathrm{OS}=\text { Sus scrofa } \mathrm{OX} \\
=9823 \mathrm{GN}=\text { MYL10 } \mathrm{PE}=4 \mathrm{SV}=3\end{array}$ & 0.016 & 0.59674 \\
\hline K4EJ64 & $\begin{array}{l}\text { MYL3 OS }=\text { Sus scrofa } \mathrm{OX}=9823 \mathrm{GN}= \\
\text { MYL3 } \mathrm{PE}=2 \mathrm{SV}=1\end{array}$ & 0.032 & 0.61319 \\
\hline
\end{tabular}

\subsection{The effect of dietary Spirulina on the piglet muscle proteome}

In the comparison of SP vs Control, two different contractile apparatus proteins were detected with differential abundance: myosin heavy chain 8 (MYH8) and alpha actin (ACTA1), with higher abundance in control and SP groups, respectively. The former takes part in actin filament binding, whereas the latter is acted upon by myosin during muscle fibre contraction. It is furthermore involved in cell organization [29]. It has been reported that farm animals under weight loss [30,31] have lower abundance of structural proteins compared to growing animals as a consequence of lower muscle development. A similar reasoning could be considered for this study. Indeed, CP digestibility and growth were lower in the groups fed with microalgae, compared to control [8]. However, since both groups had higher abundance of two different contractile apparatus proteins, these differences could reflect differential organization of the contractile process. Indeed, Xu et al. [32] found that Meishan pigs had higher abundance of ACTA1 (by comparison to Large White) in the skeletal muscle, indicating increased need of actin to promote myofibril assembly. Moreover, Fernández-Barroso et al. [29] found via a transcriptomics approach, that both MYH8 and ACTA1 genes are overexpressed in Iberian pigs with tougher meat. We found no differences regarding shear force between control and SP groups [8]. The reason(s) why microalgae inclusion causes these differences are unclear and require further investigation.

Piglets fed with $10 \%$ Spirulina had a higher abundance of glycogen debranching enzyme (GAL) which, along with glycogen phosphorylase (PYGM), are responsible for the degradation of glycogen [33]. The combined action of these enzymes generates glucose-1-P, negatively charged and unable to diffuse out of the muscle cells, where it remains available for conversion into glucose-6-P by phosphoglucomutase [33]. Glucose-6-P is then available to enter the glycolysis pathway. Interestingly, the SP group also had higher abundance of phosphopyruvate hydratase (ENO1), which acts in the glycolysis pathway, converting 2phosphoglycerate into phosphoenolpyruvate. This set of reactions
SP vs Ctrl

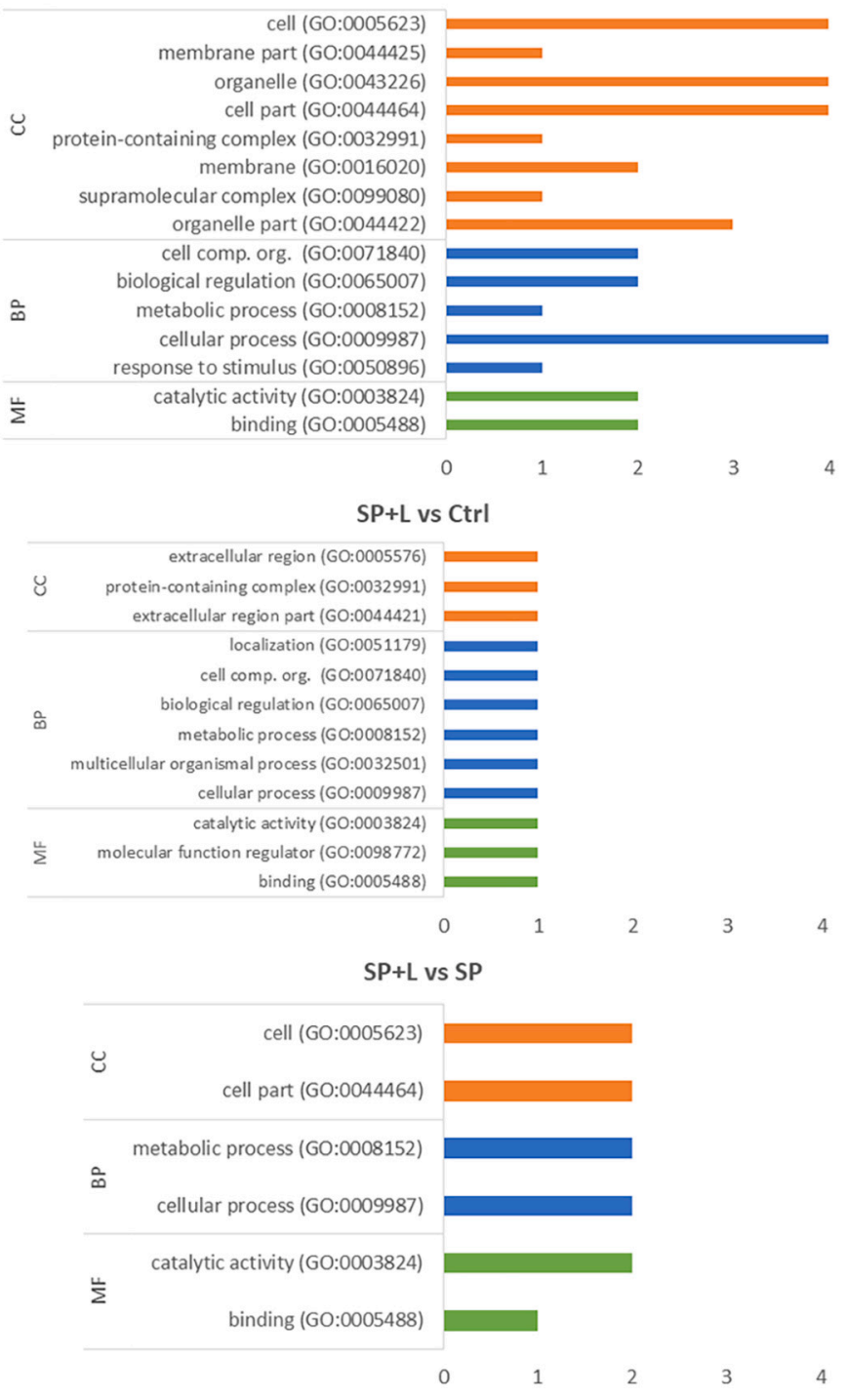

Fig. 3. Cellular components (CC - orange), biological processes (BP - blue) and molecular functions (MF - green) of proteins identified in all comparisons of the muscle proteome of piglets. (For interpretation of the references to colour in this figure legend, the reader is referred to the web version of this article.)

generates high yields of pyruvate, which becomes available for ATP production via the tricarboxylic acid (TCA) cycle. Finally, this same group of piglets had higher abundance of ATP-synthase-coupling factor 6 (ATP5J), which produces ATP from ADP in the presence of a proton gradient. Overall, these results point towards the depletion of higher energy reserves in the SP group compared to the control group. This could derive from the lower nutrient digestibility, as mentioned earlier.

Control piglets had higher abundance of alpha- 1,4 glucan phosphorylase (PYGM) compared to SP. This protein is part of the glycogenolysis pathway in tandem with GAL, when activated via phosphorylation [34]. This process is of paramount importance to the development of desirable meat quality traits post-mortem [35]. However, the higher abundance of PYGM in control piglets likely derives from their higher muscle development. It has been reported by Xu et al. [36] that PYGM is elevated during pig skeletal muscle development. In addition, the authors found higher PYGM mRNA levels in Large White vs Meishan muscle. The former has higher muscle development, characteristic of western breeds. This information is in accordance with our results regarding animal performance, as the final weight and average 


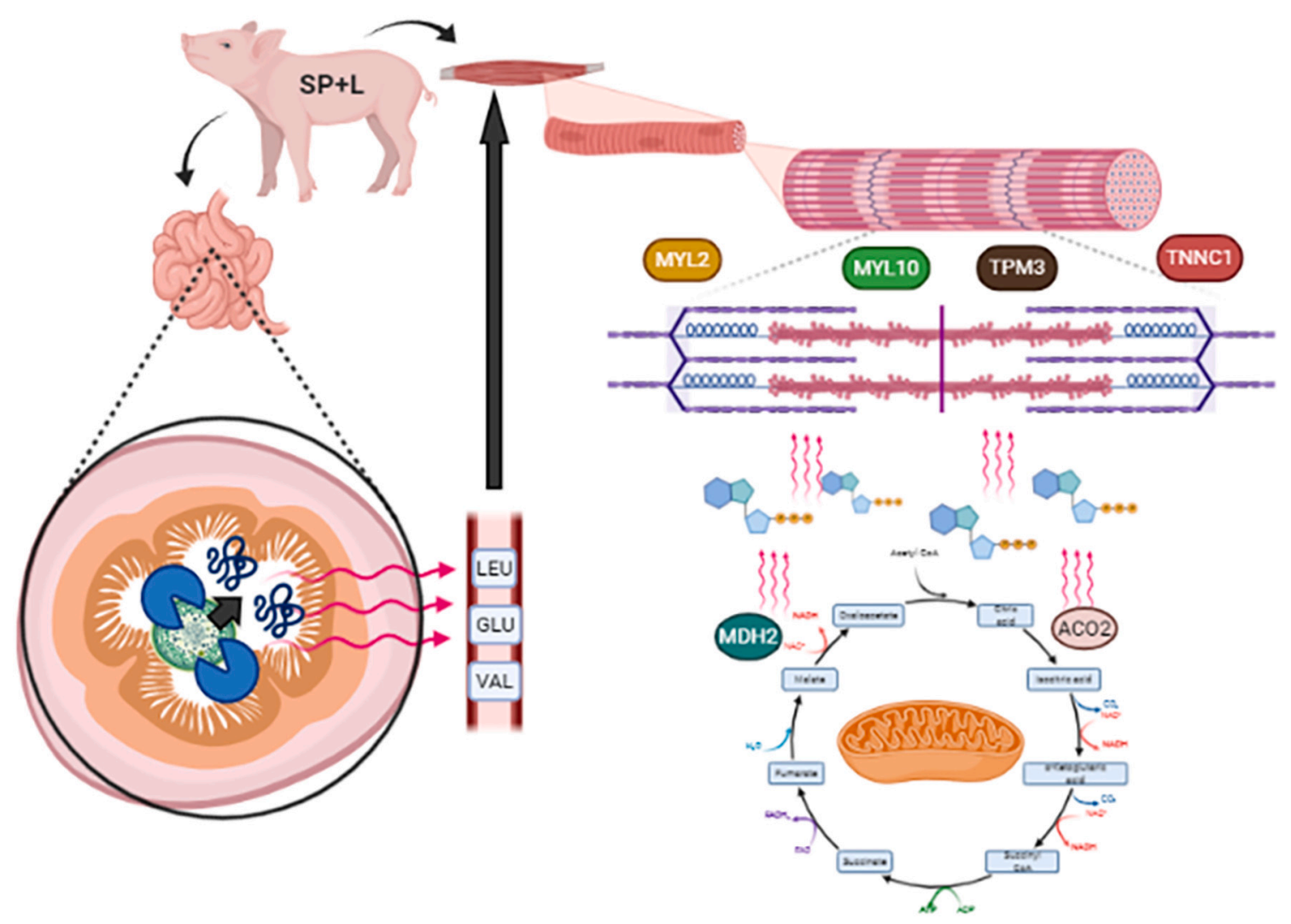

Fig. 4. Putative interpretation to explain the differential abundance in the SP + L vs SP comparison. The inclusion of lysozyme increases the availability of dietary protein to be digested by endogenous enzymes, by degrading the cell wall of Spirulina. This could lead to increased digestibility and consequent absorption of amino acids, which activates the mammalian target of rapamycin (mTOR) pathway, increasing the synthesis of muscle protein. Consequently, the needs for ATP in the muscle increase, which explains the higher abundance of TCA cycle enzymes. TPM3 - tropomyosin 3, TNNC1 - troponin C, MYL2/MYL3/MYL10 - myosin light chains, MDH2 - malate dehydrogenase, aconitate hydratase (ACO2). Created with BioRender.com.

daily gain of control pigs was significantly higher than that of Spirulinafed pigs, regardless of enzyme inclusion [8].

\subsection{Effect of Spirulina and lysozyme supplementation}

Regarding the SP $+\mathrm{L}$ vs control comparison, only 3 proteins were detected with differential abundance. L-lactate dehydrogenase and thioredoxin were highly abundant in control, whereas apolipoprotein A-I was more abundant in the SP + L group. The latter, a major component of high-density lipoproteins (HDL), was reported by Wang et al. [37] to be positively related to adipose tissue deposition in the muscle tissue of indigenous Chinese pig breeds. Indeed, APOA1 participates in the PPAR signalling pathway, which promotes adipogenic differentiation [38]. Our previous results have shown that there are no significant differences in intramuscular fat content between SP $+\mathrm{L}$ and control piglets [8]. However, they had higher abundance of some PUFA, such as 18:3n-6 and 20:3n- 6 compared to control. The higher abundance of APOA1, which also has antioxidative properties [39], could improve oxidative stability of this tissue as a reaction to PUFA enrichment. Finally, it is worth mentioning other roles in which this protein may be involved. Indeed, HDL [39] transports cholesterol from peripheral tissues towards the liver. There, it can be used for the synthesis of bile salts, which are actively secreted in the duodenum, to facilitate lipidic digestion. In the future, analysing the hepatic proteome of these piglets should unveil if APOA1 differential abundance found herein is coherent with hepatic cholesterol metabolism.

Conversely, the control group has higher abundance of LDH, a glycolytic enzyme that catalyses the conversion of lactate into pyruvate. This enzyme was reported to be highly abundant in the muscle of pigs fed with ractopamine, a supplement that promotes protein accretion and lipolysis, generating leaner meat [40]. In addition, Kwasiborsky et al. [41] reported a negative correlation between lightness $\left(\mathrm{L}^{*}\right)$ and LDH in the muscle of outdoor reared pigs. Thus, the higher abundance of LDH in the control group could occur due to increased muscle development compared to SP $+\mathrm{L}$, which is coherent with previous findings. Moreover, the higher abundance of LDH in control piglets could be related with meat colour, since these had the lowest $L^{*}$ value compared to piglets fed with diets with Spirulina inclusion [8].

\subsection{Effect of lysozyme supplementation within Spirulina diets}

Twelve proteins were detected with differential abundance in the SP $+\mathrm{L}$ vs SP comparison. The SP group had higher abundance of PYGM. This protein has already been mentioned due to its role in muscle development and glycogen metabolism. In this context, it seems that SP piglets are degrading collagen to a higher extent than $\mathrm{SP}+\mathrm{L}$. This seems to be corroborated by our results regarding feed digestibility: $\mathrm{SP}+\mathrm{L}$ had higher DM digestibility than SP [8]. This could cause SP piglets to degrade endogenous nutrient reserves to a larger extent, which does not happen in the SP $+\mathrm{L}$ group due to the positive action of the lysozyme over nutrient digestibility.

Conversely, the SP $+\mathrm{L}$ group had higher abundance of several structural/contractile apparatus proteins: tropomyosin 3 (TPM3), troponin C (TNNC1), and several myosin light chains (MYL2, MYL3, MYL10). This pattern is again likely related to improved nutrient availability. Despite the fact that crude protein digestibility had no differences between SP and SP + L groups, dry matter digestibility was improved as a consequence of enzymatic supplementation [8]. Additionally, enhanced amino acid absorption rate, particularly of branchchain amino acids (BCAA), could be causing enhanced muscle protein 
synthesis. In fact, it has been reported that supplementing diets with $14 \%$ CP with isoleucine, leucine and valine (BCAA) temporarily prevents decreased growth performance of piglets during the first twoweeks after weaning [42]. This supplementation has also been reported to enhance the growth performance of piglets fed with $17 \% \mathrm{CP}+$ BCAA to levels obtained with piglets fed with $20 \%$ CP [43]. Leucine inhibits protein degradation and promotes protein synthesis, likely to be via the mammalian target of rapamycin (mTOR) signalling pathway [44]. It has been suggested that simultaneous supplementation of all three BCAA promote muscle protein synthesis. Glutamine also promotes muscle protein synthesis, possibly through the mTOR signalling pathway [44]. Moreover, BCAA have a positive effect over intestinal development [45]. Coincidently, the SP + L group had the longest small intestine of all groups [8]. The results obtained in the present study could derive from the effect of lysozyme supplementation over amino acid digestibility. Thus, in future studies, it would be of paramount importance to evaluate individual amino acid digestibility at the ileal level, as well as plasma and tissue AA profiles, as performed before in small ruminants [46]. This would surely confirm or dismiss the aforementioned role of improved amino acid availability over muscle development based on high structural/contractile protein synthesis. Moreover, further research evaluating the impact of these dietary treatments over the gut microbiome/metaproteome would be of paramount importance. Indeed, diet is a major determinant of the gut microbiome composition [47], which has a major role on the health of the recently weaned piglet. This was recently demonstrated in piglets fed with seaweed extracts [48]. Combined with a metaproteomics approach [49] in order to assess the activity of these microorganisms, such study would contribute to determine the first impact of dietary treatments prior to tissue metabolism, providing a holistic view.

Finally, the SP + L group had higher abundance of malate dehydrogenase (MDH2) and aconitate hydratase (ACO2) compared to SP. Both of these are mitochondrial enzymes, involved in the TCA cycle, which releases stored energy via the oxidation of reserve carbohydrates, fat and/or proteins. Previous studies have indicated that the upregulation of mitochondrial TCA cycle is negatively correlated with feed efficiency in pigs, indicating that these generate lower levels of ATP in this organelle [50]. However, in the context of the present study, the higher abundance of MDH2 and ACO2 most likely derives from the increased abundance of contractile apparatus proteins, whose functions requires high input of ATP. Fig. 4 depicts the possible chain of events that explain this relationship.

\subsection{Conclusions and future perspectives}

In this study, the influence of dietary Spirulina on piglet muscle proteome was described for the first time. Additionally, the effect of dietary lysozyme supplementation was evaluated. Piglets fed with this microalga had altered muscle glycogen metabolism and endogenous nutrient mobilization, which could possibly be related with lower nutrient digestibility compared with others fed a diet without microalga. Interestingly, the SP $+\mathrm{L}$ group had higher abundance of structural and TCA cycle proteins compared to SP. Together with its beneficial effect over dry matter digestibility, it seems feasible that this differential abundance is influenced by increased availability of amino acids. Furthermore, our study also demonstrates the importance of combining novel omics approaches with other classical methods, such as tissue AA profiling.

In future studies, assessing AA digestibility, particularly at the ileal level, could validate the hypothesis of positive effect of lysozyme over AA digestibility. Also, the muscle AA profile would be helpful to assess the activity of the mTOR pathway. Additionally, the study of other tissue proteomes, such as liver and small intestine, will also be of relevance.

\section{Acknowledgements}

This work was supported by the Fundação para a Ciência e a Tecnologia (FCT, Lisbon, Portugal) grant (PTDC/CVT-NUT/5931/2014), Portugal 2020 grant (08/SI/3399/2015), CIISA (UIDB/00276/2020) and LEAF (UIDB/04129/2020). Author DR acknowledges a PhD fellowship (SFRH/BD/143992/2019) by FCT. Authors AH, JK, NG and PDE acknowledge funding by the FP7 "VetMedZg" Project (grant number 621394 https://www.vetmedzg.eu/en/) of the European Commission.

\section{Appendix A. Supplementary data}

Supplementary data to this article can be found online at https://doi. org/10.1016/j.jprot.2021.104274.

\section{References}

[1] L.M.P. Valente, A.R.J. Cabrita, M.R.G. Maia, I.M. Valente, S. Engrola, A.J. M. Fonseca, D.M. Ribeiro, M. Lordelo, C.F. Martins, L. Falcão-E-Cunha, A. M. Almeida, J.P.B. Freire, Microalgae as feed ingredients for livestock production and aquaculture, in: C.M. Galanakis (Ed.), Microalgae - Cultiv. Recover. Compd. Appl, 1st ed., Academic Press, Inc., London, 2020, pp. 239-302.

[2] M.S. Madeira, C. Cardoso, P.A. Lopes, D. Coelho, C. Afonso, Microalgae as feed ingredients for livestock production and meat quality: a review, Livest. Sci. 205 (2017) 111-121, https://doi.org/10.1016/j.livsci.2017.09.020.

[3] C.L.M. de Visser, R. Schreuder, F. Stoddard, The EU's dependency on soya bean import for the animal feed industry and potential for EU produced alternatives, OCL 21 (2014) D407, https://doi.org/10.1051/ocl/2014021.

[4] V. Fehlenberg, M. Baumann, N.I. Gasparri, M. Piquer-Rodriguez, G. Gavier-Pizarro, T. Kuemmerle, The role of soybean production as an underlying driver of deforestation in the South American Chaco, Glob. Environ. Chang. 45 (2017) 24-34, https://doi.org/10.1016/j.gloenvcha.2017.05.001.

[5] D. Coelho, P.A. Lopes, V. Cardoso, P. Ponte, J. Brás, M.S. Madeira, C.M. Alfaia, N. M. Bandarra, H.G. Gerken, C.M.G.A. Fontes, J.A.M. Prates, Novel combination of feed enzymes to improve the degradation of Chlorella vulgaris recalcitrant cell wall, Sci. Rep. 9 (2019) 1-11, https://doi.org/10.1038/s41598-019-41775-0.

[6] D. Coelho, P.A. Lopes, V. Cardoso, P. Ponte, J. Brás, M.S. Madeira, C.M. Alfaia, N. M. Bandarra, C.M.G.A. Fontes, J.A.M. Prates, A two-enzyme constituted mixture to improve the degradation of Arthrospira platensis microalga cell wall for monogastric diets, J. Anim. Physiol. Anim. Nutr. (Berl) (2019) 310-321, https://doi.org/ 10.1111/jpn.13239.

[7] S. Dillon, T. Sweeney, S. Figat, J.J. Callan, J.V. O'Doherty, The effects of lactose inclusion and seaweed extract on performance, nutrient digestibility and microbial populations in newly weaned piglets, Livest. Sci. 134 (2010) 205-207, https://doi. org/10.1016/j.livsci.2010.06.142.

[8] C.F. Martins, J. Pestana, A. David, M.R. Santos, M. Sofia, S.M. Cristina, M. Riscado, P. Mateus, P. Alexandra, A. Brás, L. Diogo, F. Maurício, J. Pedro, C. Lemos, A.M. De Almeida, J. António, M. Prates, J. Pedro, B. Freire, Effect of dietary inclusion of Spirulina on production performance, nutrient digestibility and meat quality traits in post-weaning piglets, J. Anim. Physiol. Anim. Nutr. (Berl) (2020) 1-13, https:// doi.org/10.1111/jpn.13470.

[9] J. Santos Silva, J.L. Tirapicos Nunes, Inventory and characterization of traditional Mediterranean pig production systems. Advantages and constraints towards its development, Acta Argiculturae Slov. (Supplement) (2013) 61-67.

[10] J.M. Heo, F.O. Opapeju, J.R. Pluske, J.C. Kim, D.J. Hampson, C.M. Nyachoti, Gastrointestinal health and function in weaned pigs: a review of feeding strategies to control post-weaning diarrhoea without using in-feed antimicrobial compounds, J. Anim. Physiol. Anim. Nutr. (Berl) 97 (2013) 207-237, https://doi.org/10.1111/ j.1439-0396.2012.01284.x.

[11] P.E. Urriola, J.A. Mielke, Q. Mao, Y. Hung, J.F. Kurtz, L.J. Johnston, G.C. Shurson, C. Chen, M. Saqui-salces, Evaluation of a partially de-oiled microalgae product in nursery pig diets, Transl. Anim. Sci. 1 (2018) 169-183, https://doi.org/10.1093/ tas/txy013.

[12] R. Ekmay, S. Gatrell, K. Lum, J. Kim, X.G. Lei, Nutritional and Metabolic Impacts of a Defatted Green Marine Microalgal (Desmodesmus sp.) Biomass in Diets for Weanling Pigs and Broiler Chickens, 2014, https://doi.org/10.1021/jf501155n.

[13] D.M. Ribeiro, A.A.K. Salama, A.C.M. Vitor, A. Argüello, C.T. Moncau, E.M. Santos, G. Caja, J.S. de Oliveira, J.C.C. Balieiro, L.E. Hernández-Castellano, M. Zachut, M. D. Poleti, N. Castro, S.P. Alves, A.M. Almeida, The application of omics in ruminant production: a review in the tropical and sub-tropical animal production context, J. Proteome 227 (2020) 103905, https://doi.org/10.1016/j.jprot.2020.103905.

[14] E. Bendixen, M. Danielsen, K. Hollung, E. Gianazza, I. Miller, Farm animal proteomics - a review, J. Proteome 74 (2011) 282-293, https://doi.org/10.1016/j. jprot.2010.11.005.

[15] A.M. de Almeida, E. Bendixen, Pig proteomics: a review of a species in the crossroad between biomedical and food sciences, J. Proteome 75 (2012) 4296-4314, https://doi.org/10.1016/j.jprot.2012.04.010.

[16] C. Kasper, D. Ribeiro, A.M. de Almeida, C. Larzul, L. Liaubet, E. Murani, Omics application in animal science-a special emphasis on stress response and damaging 
behaviour in pigs, Genes (Basel) 11 (2020) 1-24, https://doi.org/10.3390/ genes11080920.

[17] M. Te Pas, A. Hoekman, M. Smits, Biomarkers as management tools for industries in the pork production chain, J. Chain Netw. Sci. 11 (2011) 155-166, https://doi. org/10.3920/JCNS2011.Qpork6.

[18] V.M.R. Pires, M.S. Madeira, A.A. Dowle, J. Thomas, A.M. Almeida, J.A.M. Prates, Increased intramuscular fat induced by reduced dietary protein in finishing pigs: effects on the longissimus lumborum muscle proteome, Mol. BioSyst. 12 (2016) 2447-2457, https://doi.org/10.1039/c6mb00213g.

[19] Y. Li, J. Yin, H. Han, G. Liu, D. Deng, S.W. Kim, G. Wu, T. Li, Y. Yin, Metabolic and proteomic responses to long-term protein restriction in a pig model, J. Agric. Food Chem. 66 (2018) 12571-12579, https://doi.org/10.1021/acs.jafc.8b05305.

[20] G. Paredi, F. Mori, M.G. de Marino, S. Raboni, L. Marchi, S. Galati, A. Buschini, D. Pietro Lo Fiego, A. Mozzarelli, Is the protein profile of pig Longissimus dorsi affected by gender and diet? J. Proteomics 206 (2019) 103437, https://doi.org/10.1016/j. jprot.2019.103437.

[21] D.M. Ribeiro, J. Bandarrinha, P. Nanni, S.P. Alves, C.F. Martins, B. RJB, L. Falcão E. Cunha, A.M. Almeida, The effect of Nannochloropsis oceanica feed inclusion on rabbit muscle proteome, J. Proteomics (2020) 103783, https://doi.org/10.1016/j. jprot.2020.103783.

[22] J.R. Wiśniewski, A. Zougman, N. Nagaraj, M. Mann, Universal sample preparation method for proteome analysis, Nat. Methods 6 (2009) 359-362, https://doi.org/ 10.1038/nmeth.1322.

[23] Y. Perez-Riverol, A. Csordas, J. Bai, M. Bernal-Llinares, S. Hewapathirana, D. J. Kundu, A. Inuganti, J. Griss, G. Mayer, M. Eisenacher, E. Pérez, J. Uszkoreit, J. Pfeuffer, T. Sachsenberg, S. Yilmaz, S. Tiwary, J. Cox, E. Audain, M. Walzer, A. F. Jarnuczak, T. Ternent, A. Brazma, J.A. Vizcaíno, The PRIDE database and related tools and resources in 2019: improving support for quantification data, Nucleic. Acids Res. 47 (2019) (PubMed ID: 30395289).

[24] A. Horvatić, N. Guillemin, H. Kaab, D. McKeegan, E. O’Reilly, M. Bain, J. Kuleš, P. D. Eckersall, Quantitative proteomics using tandem mass tags in relation to the acute phase protein response in chicken challenged with Escherichia coli lipopolysaccharide endotoxin, J. Proteome 192 (2019) 64-77, https://doi.org/ 10.1016/j.jprot.2018.08.009.

[25] K. Yu, M. Matzapetakis, D. Valent, Y. Saco, A.M. De Almeida, M. Terré, A. Bassols, Skeletal muscle metabolomics and blood biochemistry analysis reveal metabolic changes associated with dietary amino acid supplementation in dairy calves, Sci. Rep. 8 (2018) 1-12, https://doi.org/10.1038/s41598-018-32241-4.

[26] K. Yu, M. Matzapetakis, A. Horvatić, M. Terré, A. Bach, J. Kuleš, N. Yeste, N. Gómez, L. Arroyo, E. Rodríguez-Tomàs, R. Peña, N. Guillemin, A.M. de Almeida, P.D. Eckersall, A. Bassols, Metabolome and proteome changes in skeletal muscle and blood of pre-weaning calves fed leucine and threonine supplemented diets, J. Proteome 216 (2020) 103677, https://doi.org/10.1016/j.jprot.2020.103677.

[27] R.C. Team, R: A Language and Environment for Statistical Computing, R Foundation for Statistical Computing, 2019. https://www.r-project.org/.

[28] H. Mi, A. Muruganujan, P.D. Thomas, PANTHER in 2013: modeling the evolution of gene function, and other gene attributes, in the context of phylogenetic trees, Nucleic Acids Res. 41 (2013) 377-386, https://doi.org/10.1093/nar/gks1118.

[29] M.Á. Fernández-Barroso, C. Caraballo, L. Silió, C. Rodríguez, Y. Nuñez, F. SánchezEsquiliche, G. Matos, J.M. García-Casco, M. Muñoz, Differences in the loin tenderness of iberian pigs explained through dissimilarities in their transcriptome expression profile, Animals 10 (2020) 1-25, https://doi.org/10.3390/ ani10091715.

[30] A.M. Ferreira, J. Grossmann, C. Fortes, T. Kilminster, T. Scanlon, J. Milton, J. Greeff, C. Oldham, P. Nanni, A.M. Almeida, The sheep (Ovis aries) muscle proteome: decoding the mechanisms of tolerance to seasonal weight loss using label-free proteomics, J. Proteome 161 (2017) 57-67, https://doi.org/10.1016/j. jprot.2017.03.020

[31] A.M. Almeida, R.G. Palhinhas, T. Kilminster, T. Scanlon, S. van Harten, J. Milton, D. Blache, J. Greeff, C. Oldham, A.V. Coelho, L.A. Cardoso, The effect of weight loss on the muscle proteome in the Damara, Dorper and Australian merino ovine breeds, PLoS One 11 (2016), e0146367, https://doi.org/10.1371/journal. pone.0146367.

[32] Y.J. Xu, M.L. Jin, L.J. Wang, A.D. Zhang, B. Zuo, D.Q. Xu, Z.Q. Ren, M.G. Lei, X. Y. Mo, F.E. Li, R. Zheng, C.Y. Deng, Y.Z. Xiong, Differential proteome analysis of porcine skeletal muscles between Meishan and Large White, J. Anim. Sci. 87 (2009) 2519-2527, https://doi.org/10.2527/jas.2008-1708.

[33] J.M. Berg, J.L. Tymoczko, L. Stryer, Section 21.1 glycogen breakdown requires the interplay of several enzymes, in: Biochemestry, 5th ed., W. H. Freeman, New York, USA, 2002. https://www.ncbi.nlm.nih.gov/books/NBK22467/.

[34] G. Wu, Principles of Animal Nutrition, Taylor \& Francis Group, Boca Raton, Florida, US, 2018.

[35] B. Zou, D. Zhao, G. He, Y. Nian, D. Da, J. Yan, C. Li, Acetylation and phosphorylation of proteins affect energy metabolism and pork quality, J. Agric. Food Chem. 68 (2020) 7259-7268, https://doi.org/10.1021/acs.jafc.0c01822.

[36] Y. Xu, W. Yu, X. Feng, H. Xie, Y. Xiong, Molecular characterization, expression patterns, and polymorphism of a differentially expressed porcine gene (PYGM) isolated by suppression subtractive hybridization and two-dimensional gel electrophoresis analysis, DNA Cell Biol. 31 (2012) 98-105, https://doi.org/ 10.1089/dna.2011.1295.

[37] Z. Wang, P. Shang, Q. Li, L. Wang, Y. Chamba, B. Zhang, H. Zhang, C. Wu, ITRAQbased proteomic analysis reveals key proteins affecting muscle growth and lipid deposition in pigs, Sci. Rep. 7 (2017) 1-11, https://doi.org/10.1038/srep46717.

[38] K. Qiu, X. Zhang, L. Wang, N. Jiao, D. Xu, J. Yin, Protein expression landscape defines the differentiation potential specificity of adipogenic and myogenic precursors in the skeletal muscle, J. Proteome Res. 17 (2018) 3853-3865, https:// doi.org/10.1021/acs.jproteome.8b00530.

[39] A. Von Eckardstein, M. Hersberger, L. Rohrer, Current understanding of the metabolism and biological actions of HDL, Curr. Opin. Clin. Nutr. Metab. Care 8 (2005) 147-152, https://doi.org/10.1097/00075197-200503000-00007.

[40] B.R.C. Costa-Lima, S.P. Suman, S. Li, C.M. Beach, T.J.P. Silva, E.T.F. Silveira, B. M. Bohrer, D.D. Boler, Dietary ractopamine influences sarcoplasmic proteome profile of pork Longissimus thoracis, Meat Sci. 103 (2015) 7-12, https://doi.org/ 10.1016/j.meatsci.2014.12.008.

[41] A. Kwasiborski, T. Sayd, C. Chambon, V. Santé-Lhoutellier, D. Rocha, C. Terlouw, Pig Longissimus lumborum proteome: part II: relationships between protein content and meat quality, Meat Sci. 80 (2008) 982-996, https://doi.org/10.1016/ j.meatsci.2008.04.032.

[42] S. Spring, H. Premathilake, C. Bradway, C. Shili, U. DeSilva, S. Carter, A. Pezeshki, Effect of very low-protein diets supplemented with branched-chain amino acids on energy balance, plasma metabolomics and fecal microbiome of pigs, Sci. Rep. 10 (2020) 1-16, https://doi.org/10.1038/s41598-020-72816-8.

[43] S. Zhang, S. Qiao, M. Ren, X. Zeng, X. Ma, Z. Wu, P. Thacker, G. Wu, Supplementation with branched-chain amino acids to a low-protein diet regulates intestinal expression of amino acid and peptide transporters in weanling pigs, Amino Acids 45 (2013) 1191-1205, https://doi.org/10.1007/s00726-013-1577-y.

[44] G. Wu, Amino acids: metabolism, functions, and nutrition, Amino Acids 37 (2009) 1-17, https://doi.org/10.1007/s00726-009-0269-0.

[45] Q. Mou, H.S. Yang, Y.L. Yin, P.F. Huang, Amino acids influencing intestinal development and health of the piglets, Animals 9 (2019), https://doi.org/10.3390/ ani9060302.

[46] D.M. Ribeiro, M.S. Madeira, T. Kilminster, T. Scanlon, C. Oldham, J. Greeff, J.P. B. Freire, M.P. Mourato, J.A.M. Prates, A.M. Almeida, Amino acid profiles of muscle and liver tissues of Australian Merino, Damara and Dorper lambs under restricted feeding, J. Anim. Physiol. Anim. Nutr. (Berl) (2019) 1-8, https://doi. org/10.1111/jpn.13148.

[47] R. Isaacson, H.B. Kim, The intestinal microbiome of the pig, Anim. Health Res. Rev. 13 (2012) 100-109, https://doi.org/10.1017/S1466252312000084.

[48] S. Vigors, J. O'Doherty, R. Rattigan, T. Sweeney, Effect of supplementing seaweed extracts to pigs until d35 post-weaning on performance and aspects of intestinal health, Mar. Drugs. 19 (2021) 1-14, https://doi.org/10.3390/md19040183.

[49] J. Tröscher-Mußotter, B. Tilocca, V. Stefanski, J. Seifert, Analysis of the bacterial and host proteins along and across the porcine gastrointestinal tract, Proteomes 7 (2019), https://doi.org/10.3390/proteomes7010004.

[50] L. Fu, Y. Xu, Y. Hou, X. Qi, L. Zhou, H. Liu, Y. Luan, L. Jing, Y. Miao, S. Zhao, H. Liu, X. Li, Proteomic analysis indicates that mitochondrial energy metabolism in skeletal muscle tissue is negatively correlated with feed efficiency in pigs, Sci. Rep. 7 (2017) 1-8, https://doi.org/10.1038/srep45291. 